\title{
Experimental and Theoretical Study of Calcium Sulphate Precipitation in Porous Media Using Glass Micromodel
}

\author{
S.M. Ghaderi ${ }^{1}$, R. Kharrat ${ }^{2 *}$ and H.A. Tahmasebi ${ }^{3}$ \\ 1 Department of Chemical and Petroleum Engineering, University of Calgary, Calgary, Alberta - Canada \\ 2 Petroleum University of Technology Research Center, Tehran - Iran \\ 3 Azad University (Branch of Science and Research), Tehran - Iran \\ e-mail: smghader@ucalgary.ca - kharrat@put.ac.ir - hatahmasebi@yahoo.com \\ * Corresponding author
}

\begin{abstract}
Résumé - Étude théorique et expérimentale de la précipitation de sulfate de calcium en milieu poreux sur micromodèle de verre - Le mélange de deux eaux incompatibles lors d'injection d'eau donne habituellement lieu à précipitation et formation de dépôts minéraux dans les milieux poreux. Ces dépôts qui réduisent la porosité et surtout la perméabilité de la roche ont une influence considérable sur les performances des scénarios d'injection d'eau. Dans cette étude, une série d'expériences a permis d'étudier l'effet de différents paramètres sur la précipitation progressive de sulfate de calcium. Il s'agit notamment de la température, de la concentration des saumures mélangées, de la pression et du débit. En raison de sa transparence, un micromodèle de réseau représentatif d'un grès mouillable à l'eau a été utilisé comme support poreux et a permis d'observer facilement la formation et la distribution des dépôts minéraux. De plus, le suivi du déplacement des particules solides est largement facilité par le nouveau dispositif expérimental proposé. Les photos de coupes obtenues en microscopie montrent que le dépôt est initié sur les parois et les seuils des pores, qu'il se propage vers l'intérieur de ces pores, et que les cristaux solides ont une forme en crête de coq. Pour une meilleure compréhension de l'effet de chacun des paramètres mentionnés ci-dessus, il a été tracé une courbe de la réduction de perméabilité en fonction du volume de solution de saumure injectée dans les pores. Les résultats ont indiqué que l'augmentation de la température, de la concentration de saumure et du débit conduisent à une augmentation de la tendance au dépôt de minéraux. La pression n'a qu'un rôle mineur sur le développement du processus. Le dépôt de $\mathrm{CaSO}_{4}$ se modélise comme une fonction de réduction de la perméabilité dépendante des différents paramètres. C'est pourquoi il a été proposé une fonction exponentielle (de corrélation) qui intègre sous une forme adimensionnelle tous les paramètres physiques ayant une influence sur le comportement du système. Le nombre de Reynolds, l'index de précipitation et l'écart par rapport aux conditions d'équilibre constituent le fondement de cette corrélation. Les exposants ajustables de l'équation ont été déterminés et optimisés au moyen d'un algorithme génétique. Cette corrélation significative peut également prédire, avec une précision raisonnable, les résultats issus d'expériences sur carottes.
\end{abstract}

Abstract - Experimental and Theoretical Study of Calcium Sulphate Precipitation in Porous Media Using Glass Micromodel - Mixing of two incompatible waters in water injection projects is usually associated with mineral scale formation and deposition in porous media. Deposition process dramatically affects the performance of water injection scenarios by reduction of porosity and mainly permeability of the rock. In this study, a series of experiments has been conducted to investigate the effect of different parameters on the gradual process of Calcium Sulphate precipitation. These include 
temperature, concentration of mixing brines, pressure, and flow rate. Due to the visual nature of the glass micromodel, a glass sandstone pattern with water-wet characteristics was used as porous medium to easily observe the scaling formation and distribution. In addition, tracing the movement of the solid particles is highly facilitated in this newly suggested experimental setup. The captured photos in microscopy scanning show that the deposition is initiated from the walls of the pores and throats and extend toward the middle space of porous medium and solid crystals look like chicken roost. For better understanding of the effect of any aforementioned parameter, the related permeability reduction curve versus injected pore volume of the brine solutions was plotted. The results indicated that as the temperature, brine concentration, and flow rate increase the scaling tendency increases as well. The pressure has a minor role on the process development. Deposition of $\mathrm{CaSO}_{4}$ manifests a functional form of permeability reduction due to the effect of different parameters. Therefore, an exponential functionality (correlation) was proposed which incorporates all physical parameters that affect the behavior of the system in dimensionless form. Reynolds number, scaling index, and deviation from equilibrium conditions are the backbone of this correlation. The adjustable exponents of the equation was determined and optimized by means of Genetic Algorithm optimization scheme. This meaningful correlation can also predict the core extracted data with reasonable accuracy.

\section{NOMENCLATURE}

$\begin{array}{ll}A & \text { Area }\left(\mathrm{m}^{2}\right) \\ a & \text { Activity of species }(\mathrm{M}) \\ C & \text { Concentration }(\mathrm{M}) \\ c c & \text { Cubic centimeter }\left(\mathrm{cm}^{3}\right) \\ I P & \text { Ionic product }\left(\mathrm{M}^{2}\right) \\ I S & \text { Molar ionic strength }(\mathrm{M}) \\ K_{i} & \text { Initial permeability (mD) } \\ K_{s p} & \text { Apparent solubility product }\left(\mathrm{M}^{2}\right) \\ K_{s p}^{0} & \text { Solubility product }\left(\mathrm{M}^{2}\right) \\ L & \text { Length }(\mathrm{m}) \\ M & \text { Molarity }(\mathrm{mol} / \text { liter of solution) } \\ m D & \text { Mili-darcy } \\ M X & \text { Solute } \\ P & \text { Pressure }(\mathrm{KPa}) \\ P P M & \text { Parts Per Million } \\ P V_{i n j} & \text { Injected pore volume } \\ Q & \text { Flow rate }\left(\mathrm{m}^{3} / \mathrm{s}\right) \\ R e & \text { Reynolds number } \\ S S(S I) & \text { Supersaturation }(\mathrm{Scaling} \text { index }) \\ T & \text { Temperature }\left({ }^{\circ} \mathrm{C}\right) \\ t & \text { Time }(\mathrm{s}) \\ u & \text { Velocity (m/s) } \\ u_{a} & \text { Apparent velocity (m/s) }\end{array}$

\section{Greek}

$\alpha_{1} \sim \alpha_{4}$ Adjustable exponents

$\beta \quad$ Proportionality constant

$\beta_{1} \sim \beta_{2}$ Adjustable exponents

$\gamma \quad$ Activity coefficient $\left(\mathrm{M}^{2}\right)$

$\Delta \quad$ Difference

$\varepsilon \quad$ Stoichiometry coefficient (M)

$\mu \quad$ Viscosity (mPa.s)

$\phi \quad$ Porosity

\section{Subscripts}

$\begin{array}{ll}a q & \text { Aqueous phase } \\ i & \text { Component } i \\ s & \text { Solid }\end{array}$

\section{INTRODUCTION}

Scale deposition due to flowing of fluids containing incompatible brine solutions has been a serious concern in the oil field operations. Occurrence of the deposition within the porous media of the reservoir causes formation damage and in the production facilities results in blockage and hence subsequent operational problems [1-3].

Among different kinds of potential scales, carbonate and sulphate scales are the ones, which are mostly encountered in the oil field [4-6]. While the occurrence of carbonate scales is attributed to the changes in $\mathrm{pH}$ and pressure, the formation of the sulphate results from mixing of incompatible brines. Injection of sea water as a recovery method and for pressure maintenance is a common practice in the oil industry. The injection brings incompatible fluids, formation water, and sea water, into close contact and therefore calcium and strontium sulphates are more likely to be present in the field [5-8].

Different available theoretical methods are capable of calculating the amount of scale that one may expect from a given blend of two waters, under certain condition of temperature, $\mathrm{pH}$, and composition. Although, these methods sometimes accurately predict the amount of formed scales, they say nothing about the potential of damaging in any porous media [10].

Conventional laboratory tests namely core and sand pack experiments are the main methods of evaluating both scaling and formation damage. However, it is difficult to observe the 
scaling formation and distribution directly with these methods [11]. The most important advantage of applying glass micromodel is its transparent feature that allows studying flow related phenomena in the pore structure with the help of microscopy. The most popular hypothetical glass micromodel, is the network model which is produced based on a real pore structure. The visual micromodel studies so far provided useful experimental evidence at pore level, which could clarify the occurrence of important events at pore and microscopic scale [12]. These unique features encouraged us to investigate a complicated phenomenon such as scale deposition during fluid flow in a closer view by this mean.

This paper introduces an easy and visual method for the evaluation of the extent of formation damage, which could result from formation and deposition of $\mathrm{CaSO}_{4}$ scale within the porous media. Glass micromodel with water-wet characteristics is the model used in this work. The change in the permeability of the porous media under the effect of different conditions of temperature, concentration of blending solutions, and flow rate has been determined. A correlation based on the dimensionless analysis of effective parameters is presented. This work shows that the micromodel has the potential to be used in this kind of study to investigate wider range of variable parameters.

\section{THEORETICAL BACKGROUND}

Inorganic scaling is a process of deposition of scales from aqueous solutions of minerals, referred to as brines, when they become supersaturated as a result of alteration of their thermodynamic state and chemical equilibria $[13,14]$. In the following section, some key terms regarding the process of calcium sulphate deposition are given.

\subsection{Solubility Product}

When a sufficiently large amount of solute is maintained in contact with a limited amount of solvent, dissolution occurs continuously until the solution reaches a state when the reverse process becomes equally important. This reverse process is the return of dissolved species (atoms, ions, or molecules) to the undissolved state, a process called precipitation. When dissolution and precipitation occur continuously and at the same rate, the amount of dissolved solute present in a given amount of solvent remains constant with time. The process is one of dynamic equilibrium and the solution in this state of equilibrium is known as a saturated solution $[15,16]$.

A solution that contains less solute than required for saturation is called an unsaturated solution. A solution, whose concentration is higher than that of a saturated solution due to any reason, such as change in temperature is said to be supersaturated solution. Both unsaturated and saturated solutions are stable and can be stored indefinitely whereas supersaturated solutions are generally unstable $[15,16]$.
Solubility data of solutes provides a basis to establish saturation condition. A convenient method of discussing the solubility of a solute is by means of a solubility product $\left(K_{s p}^{0}\right)$ Consider the addition of a solute $M X(s)$ to distilled water. At the limit of solubility, there is a dynamic equilibrium, which can be represented as follow [15]:

$$
M X(s) \leftrightarrow M_{a q}^{+}+X_{a q}^{-}
$$

and the equilibrium constant, for the solubility process is given as [15]:

$$
K_{s p}^{0}=\frac{a\left[M^{+}\right] \cdot a\left[X^{-}\right]}{a[M X]}
$$

Since the activity, $a$, of a pure solid $M X(s)$ is unity, the equilibrium expression then simplifies to [15]:

$$
K_{s p}^{0}=a\left[M^{+}\right] \cdot a\left[X^{-}\right]
$$

$K_{s p}^{0}$ is known as the solubility product or sometimes the thermodynamic solubility product and it is a function of temperature and invariant with the ionic strength of the solution [15]. In any aqueous solution containing $M$ and $X$ ions, as long as the activities $a\left[M^{+}\right]$and $a\left[X^{-}\right]$are such that their product is greater than $K_{s p}^{0}$ then some solid $M X(s)$ should precipitate until the product of $a\left[\mathrm{M}^{+}\right]$and $a\left[X^{-}\right]$ becomes equal to $K_{s p}^{0}$. With respect to concentration of dissolved species then:

$$
K_{s p}^{0}=C\left[M^{+}\right] \cdot C\left[X^{-}\right] \cdot \gamma\left[M^{+}\right] \cdot \gamma\left[X^{-}\right]
$$

that gives the following relationship [15]:

$$
K_{s p}=\frac{K_{s p}^{0}}{\gamma\left[M^{+}\right] \cdot \gamma\left[X^{-}\right]}
$$

$K_{s p}$ is known as the apparent solubility product and is related to the thermodynamic solubility product as follows [15].

If the ionic strength of the aqueous environment is low, the activity coefficient $(\gamma)$ is unity, i.e. ideal behavior of solution is approached. In this situation, activity and concentration can be equated and the above expression reduces to an approximate form $[15,16]$ :

$$
K_{s p} \approx K_{s p}^{0}
$$

and:

$$
K_{s p}^{0} \approx C\left[M^{+}\right] . C\left[X^{-}\right]
$$

\section{2 lonic Strength}

The concentration of brine is typically represented by the brine's total dissolved solids (TDS). However, for matters relating to solubility and scaling, a more appropriate representation of the brine concentration is its ionic strength $(I S) . I S$ is defined as [16]:

$$
I S=\frac{1}{2} \sum_{i} m_{i} z_{i}^{2}
$$


where:

- $z_{i}$ : charge on each component in the solution;

- $m_{i}$ : molal concentration of each component in the solution.

\section{3 lonic Product}

The ionic product $(I P)$ can be computed by the following formula for solute $M X$ [16]:

$$
I P=C_{M} \cdot C_{X}
$$

where:

- $C_{M, X}$ average concentration of $M$ and $X$ ions in the supersaturated solution.

For each mixing ratio, the molar concentration of each component in the available base solution is multiplied by the corresponding ratios and added together to get the mixture concentration of the desired ratio [16].

\subsection{Supersaturation (Scale Index)}

The scaling index of a solution is defined as [17-19]:

if:

$$
S S(S I)=\log \left(\frac{I P}{K_{s p}}\right)
$$

- IP $<K_{s p}$ : the brine will be undersaturated with respect to $M X$ and it will not form scale. The $S S$ in this case will be less than 1.0;

- $I P=K_{s p}$ : the brine will be saturated and $S S$ will be 1.0;

- $I P>K_{s p}$ : the brine will be supersaturated and may form scale. The $S S$ will be greater than 1.0.

While supersaturation is a good indicator of the scaling tendency of a solution, it does not predict when and how fast scale will form. For such an exercise, the kinetics of scale formation must be known. The kinetics of a reaction determines how fast a reaction proceeds in order to take the reacting system towards thermodynamic equilibrium. The kinetics is influenced by several factors with temperature being the most important. The precipitation rates for different salts vary significantly. The degree of supersaturation determines if a salt will precipitate or not, the kinetics will tell us how fast the precipitation reaction proceeds. It is therefore necessary to include kinetic considerations when evaluating the scaling potential of a system [17-19].

\section{EXPERIMENTAL SETUP AND PROCEDURE}

In this study, all the experiments were conducted at atmospheric pressure. A schematic diagram of the experimental setup is shown in Figure 1. It consists of the following structure and equipment. The micromodel holder is placed within a water bath to conduct the experiment at a constant

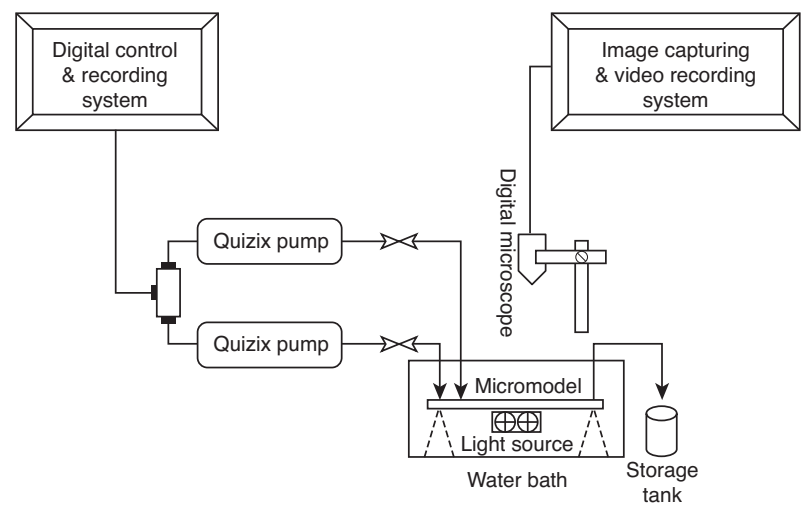

Figure 1

Schematic representation of the micromodel setup.

temperature (maximum error: $+/-0.5^{\circ} \mathrm{C}$ ). A high resolution digital microscope, which is equipped with a video recording system was used. A precise pressure transducer and two low rate pumps were used to control the fluid flow from two transfer vessels (solution tanks) to the micromodel. The micromodel was connected to the flow lines by a specially designed clamping system. It is worthy to mention that the flow lines should have high thermal conductivity and proper length for preheating of the solutions to be completed prior entrance to the porous medium (glass micromodel). For this purpose, long thin copper lines were chosen and coiled within the water bath. As the brine solutions passed through these coils, they were warmed up to the water bath temperature. Two pumps were used to inject brine solutions at the specific flow rate previously established.

\subsection{Fluids}

Solutions of pure Calcium Chloride $\left(\mathrm{CaCl}_{2}\right)$ and pure Sodium Sulphate $\left(\mathrm{Na}_{2} \mathrm{SO}_{4}\right)$ were dissolved in distilled water at various concentrations. The concentration of the solutions was chosen in such a way that results in brine solutions of the desired level of supersaturation. For example, to obtain a 0.05 molar $\mathrm{CaSO}_{4}$ solution, both solutions of $\left(\mathrm{CaCl}_{2}\right)$ and $\left(\mathrm{Na}_{2} \mathrm{SO}_{4}\right)$ with molar concentration of 0.1 were injected at equal rates to produce a 50:50 mixture at the pattern inlet. The following relation is the governing equation for calcium sulphate precipitation:

$$
\varepsilon \mathrm{CaCl}_{2}+\varepsilon \mathrm{Na}_{2} \mathrm{SO}_{4} \leftrightarrow \frac{\varepsilon}{2} \mathrm{CaSO}_{4}+\frac{\varepsilon}{2} \mathrm{NaCl}
$$

where $\varepsilon$ is the molar concentration of the injected solutions. Note that, after mixing of the solutions the total volume increases by a factor of two so the final solution concentration is half of the initial solutions. 
The solubility data and the supersaturation values (the last column in Tab. 1 through Tab. 3) at different temperature and atmospheric pressure were calculated based on the algorithm by Yuan and Tod [4]. In this model, the electrolyte ion activity coefficients were calculated by the Pitzer equation. The algorithm has proved to generate accurate and reliable data over wide range of solutions compositions and temperatures [4].

\subsection{Measurement of Micromodel Properties}

The presented properties of the micromodel patterns (column 2 and 3 in Tab. 1 through Tab. 3) have been calculated based on the procedure outlined below.

\subsubsection{Permeability}

Micromodel permeability was determined by measuring the pressure drop/flow rate response. Distilled water was injected into the micromodel at specific injection flow rate, and the corresponding differential pressure drop between the injection port and the production port was measured by a differential pressure transmitter. Four different flow rate and pressure drop data sets were obtained for each model. Flow rate data were plotted versus corresponding pressure drop values and a straight line was passed through the origin and the data set points. The slope of this line was used in Darcy's law to obtain permeability of the glass pattern. The average permeability of the patterns was approximately $2000 \mathrm{mD}$.

\subsubsection{Porosity}

The porosity of micromodel was measured by an image analysis technique using Adobe Photoshop ${ }^{\circledR}$ CS3. First each micromodel was fully saturated with colored distilled water and was photographed by a high resolution camera. Images captured by camera were loaded into the image analysis software. Colored and total area of each micromodel was estimated. Dividing the value of colored area to the total area gives the relative value of colored volume (pore volume) to

TABLE 1

Experimental conditions in investigating the effect of injected solution temperature

\begin{tabular}{|c|c|c|c|c|c|c|c|c|c|c|}
\hline \multirow{3}{*}{ Run } & \multicolumn{2}{|c|}{ Pattern properties } & \multicolumn{3}{|c|}{ Operating conditions } & \multicolumn{4}{|c|}{ Injected brine concentration } & \multirow{3}{*}{$\begin{array}{c}\text { Supersaturation } \\
\text { Ave. SS }\end{array}$} \\
\hline & \multirow{2}{*}{$\phi(\%)$} & \multirow{2}{*}{$K(\mathrm{mD})$} & \multirow{2}{*}{ Flow rate $(\mathrm{cc} / \mathrm{min})$} & \multirow{2}{*}{ Exp. duration (min) } & \multirow{2}{*}{ Temp. $\left({ }^{\circ} \mathrm{C}\right)$} & \multicolumn{2}{|c|}{$\mathrm{Ca}^{+2}$} & \multicolumn{2}{|c|}{$\mathrm{SO}_{4}^{-2}$} & \\
\hline & & & & & & $\mathrm{M}$ & PPM & M & PPM & \\
\hline 1 & 37.5 & 2010 & 0.008 & 96 & 70 & 0.05 & 2004 & 0.05 & 4803 & 1.7 \\
\hline 2 & 38.6 & 1993 & 0.008 & 95 & 80 & 0.05 & 2004 & 0.05 & 4803 & 2.0 \\
\hline 3 & 40.1 & 1994 & 0.008 & 90 & 95 & 0.05 & 2004 & 0.05 & 4803 & 2.1 \\
\hline
\end{tabular}

TABLE 2

Experimental conditions in investigating the effect of injected solution concentration

\begin{tabular}{|c|c|c|c|c|c|c|c|c|c|c|}
\hline \multirow{3}{*}{ Run } & \multicolumn{2}{|c|}{ Pattern properties } & \multicolumn{3}{|c|}{ Operating conditions } & \multicolumn{4}{|c|}{ Injected brine concentration } & \multirow{3}{*}{$\begin{array}{c}\text { Supersaturation } \\
\text { Ave.SS }\end{array}$} \\
\hline & \multirow{2}{*}{$\phi(\%)$} & \multirow{2}{*}{$K(\mathrm{mD})$} & \multirow{2}{*}{ Flow rate $(\mathrm{cc} / \mathrm{min})$} & \multirow{2}{*}{ Exp. duration (min) } & \multirow{2}{*}{ Temp. $\left({ }^{\circ} \mathrm{C}\right)$} & \multicolumn{2}{|c|}{$\mathrm{Ca}^{+2}$} & \multicolumn{2}{|c|}{$\mathrm{SO}_{4}^{-2}$} & \\
\hline & & & & & & M & PPM & M & PPM & \\
\hline 4 & 38.9 & 1989 & 0.008 & 96 & 80 & 0.015 & 601 & 0.015 & 1440 & 1.55 \\
\hline 2 & 38.6 & 1993 & 0.008 & 96 & 80 & 0.05 & 2004 & 0.05 & 4803 & 2.0 \\
\hline 5 & 39.2 & 2010 & 0.008 & 96 & 80 & 0.07 & 2805 & 0.07 & 6721 & 2.4 \\
\hline
\end{tabular}

TABLE 3

Experimental conditions in investigating the effect of injected solution flow rate

\begin{tabular}{|c|c|c|c|c|c|c|c|c|c|c|}
\hline \multirow{3}{*}{ Run } & \multicolumn{2}{|c|}{ Pattern properties } & \multicolumn{3}{|c|}{ Operating conditions } & \multicolumn{4}{|c|}{ Injected brine concentration } & \multirow{3}{*}{$\begin{array}{c}\text { Supersaturation } \\
\text { Ave. SS }\end{array}$} \\
\hline & \multirow{2}{*}{$\phi(\%)$} & \multirow{2}{*}{$K(\mathrm{mD})$} & \multirow{2}{*}{ Flow rate $(\mathrm{cc} / \mathrm{min})$} & \multirow{2}{*}{ Exp. duration (min) } & \multirow{2}{*}{ Temp. $\left({ }^{\circ} \mathrm{C}\right)$} & \multicolumn{2}{|c|}{$\mathrm{Ca}^{+2}$} & \multicolumn{2}{|c|}{$\mathrm{SO}_{4}^{-2}$} & \\
\hline & & & & & & M & PPM & M & PPM & \\
\hline 6 & 38 & 1991 & 0.004 & 190 & 80 & 0.05 & 2004 & 0.05 & 4803 & 2.0 \\
\hline 2 & 38.6 & 1993 & 0.008 & 96 & 80 & 0.05 & 2004 & 0.05 & 4803 & 2.0 \\
\hline 7 & 38.2 & 1993 & 0.012 & 66 & 80 & 0.05 & 2004 & 0.05 & 4803 & 2.0 \\
\hline
\end{tabular}


the total (bulk) volume and thus value of porosity for each micromodel pattern. After the porosity measurement was done, the pattern should be flooded by alcohol to completely remove the coloring agent (Methylene Blue) and retain the original surface properties of the glass. The average porosity of the patterns was around 0.39 .

\subsubsection{Pore Volume}

During injection of colored water with known flow rate into the micromodel, for a known incremental time the incremental area occupied by colored water was measured using the image analysis technique. Incremental time multiply by injection flow rate divided by incremental area is equal to average etched height on that region. The pore volume is equal to areal porosity multiply by average etched height.

\section{EXPERIMENTAL PROCEDURE}

For investigation of the precipitation process two transfer vessels were filled with the two related incompatible solution pair $\left(\mathrm{CaCl}_{2}, \mathrm{Na}_{2} \mathrm{SO}_{4}\right)$. The pattern holder assembly and the flow lines were then placed inside the water bath and heated to the target temperature. The system was left 1 hour for temperature equilibrium to be attained. A flooding test was started by setting both Quizix pumps at the same rate (ranging from $0.008 \mathrm{cc} / \mathrm{min}$ to $0.012 \mathrm{cc} / \mathrm{min}$ ). Thus, the two solutions were always injected into the pattern at a mixing ratio of 50:50 and the total flow rate through the pattern was twice the rate of each pump.

The differential pressure and injected pore volume of each solution were recorded continuously by the implemented software on the connected computer. Each run was terminated when the injected pore volume reached the approximate value of 28 . This criterion was chosen to set a datum for comparison of permeability reduction for different conditions. In addition, in some of the preliminary runs it was indicated that for most of the runs the pressure drop stabilizes after this quantity of pore volume injection which signaled the attainment of a steady-state $\mathrm{Ca}^{+2}$ concentration profile across the pattern [6].

\subsection{Preliminary Runs}

Core and sand pack experiments are the main methods of studying scaling mechanisms. However, it is difficult to observe the scaling formation and distribution directly by means of these methods. So the results and discussions in this study are related to the scaling and damage mechanisms in porous media using visual glass micromodels.

Design and proper selection of the type of porous media are the most important parts in obtaining reliable data from micromodel experiments. The sandstone pattern etched on

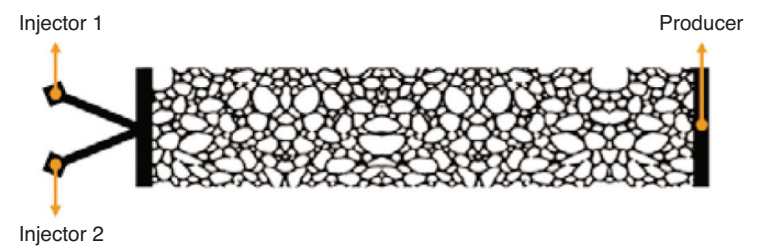

Figure 2

First design of the micromodel pattern used in this study.

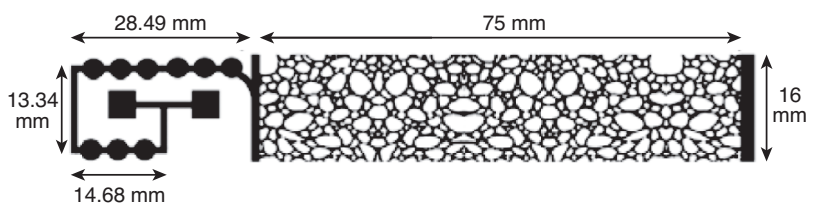

Figure 3

Configuration and dimensions of the pattern employed in this study.

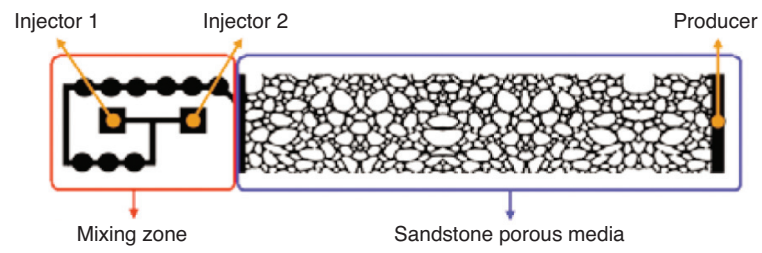

Figure 4

Different parts of the micromodel pattern.

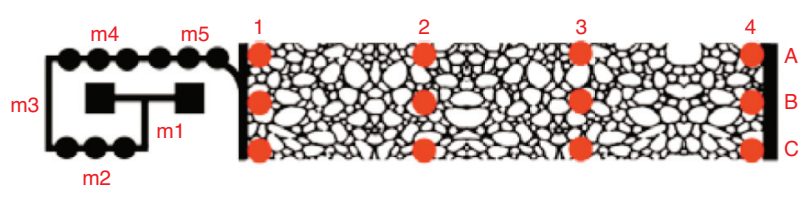

Figure 5

Different zones in the micromodel pattern.

glass was selected as the model for porous medium. This type of porous media consists of randomly distributed grains with different sizes and orientations. The structures of pores and throats therefore, are mostly similar to a real reservoir rock.

The first design of the model is shown in Figure 2. The design was quite simple; two straight conduits deliver the brine solution to the inlet of the pattern. It was observed that at the end of the flooding process, the scaling deposition zone was limited only to a small region of the pattern close to the production port. It was concluded that this design was not 
effective. The initial regions of the pattern act as a mixing zone and therefore the scale particles do not have enough time to precipitate out of the solution in these regions. In addition, the flow velocity causes the entrainment of any probable precipitated solid particle in these regions.

To overcome the aforementioned problems the design of pattern was modified with the result illustrated in Figure 3. The final model consists of two parts i.e. the mixing zone and the desired pattern (see Fig. 3 and 4). The mixing zone is a relatively long path with variable width. The long path of the mixing zone causes the solutions to stay in contact for enough time to initiate the precipitation reaction. Variable width (variable cross section) along the mixing zone results in thorough mixing of the involved solution.

The scale deposition during flooding process (dynamic behavior) was observed in one of the preliminary runs. The experiment was conducted at the following conditions:

- temperature: $25.0^{\circ} \mathrm{C}$;

- pressure: atmospheric;

- solutions: 0.14 molar solutions of $\mathrm{CaCl}_{2}$ and $\mathrm{Na}_{2} \mathrm{SO}_{4}$;

- supersaturation Index: 2.1;

- flow rate: $0.01 \mathrm{cc} / \mathrm{min}$;

- porous media structure: regular network.

For recognizing a suitable pore, the model was flooded by Methylene Blue. After choosing the suitable point (Fig. 6a), the model was cleaned out of the coloring agent by alcohol flooding alternating with water flooding to retain the surface properties of the glass (Fig. 6b). The evolution of the crystallization process in the vicinity of the considered pore has been demonstrated in Figure 6c through Figure $6 \mathrm{f}$.

\subsection{Precipitation of $\mathrm{CaSO}_{4}$}

A total of 7 runs were performed to investigate the effect of temperature (T), concentration supersaturation (SS), and flow rate $(Q)$ on the probability and extension of deposited area. Obtaining the information of permeability reduction trend versus the injected pore volume of the brine solutions was the final target of this study.

As mentioned earlier, Figure 3 and Figure 4 depict the micromodel pattern and the configuration that was designed for this study. Figure 5 shows different parts of the pattern along its length. In this figure, letter $m$ marks the mixing zone which plays a crucial role in the success of this study. The importance of this role will be explained in more detail in the next section. At zone $m 1$, the brine solutions first come into contact. As the solutions enter the mixing zone they mix thoroughly. Since the porous pattern has very tiny apertures (pores and throats) the scale particles commence to precipitate out of the solution starting from the inlet region of the pattern (zone 1) to the end region (zone 4). The scaling position in porous media is absolutely random. The scale

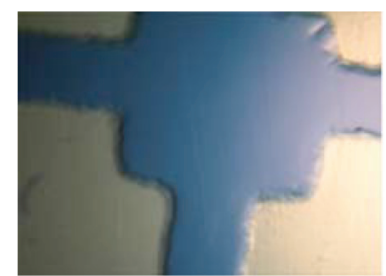

a) A specific pore is selected.

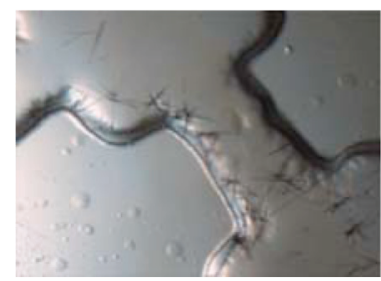

c) Nucleation stage, $t=30 \mathrm{~min}$.

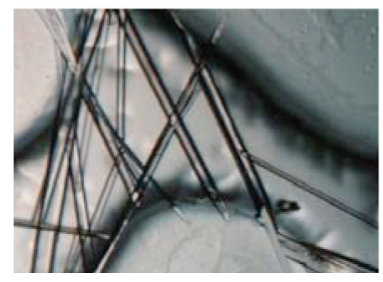

e) Growth of crystals, $t=60 \mathrm{~min}$.

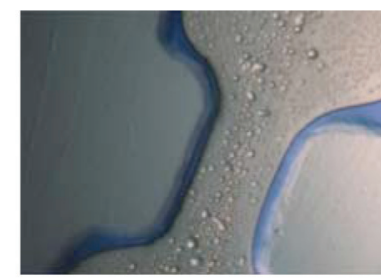

b) Flooding the pattern with alcohol alternating with distilled water.

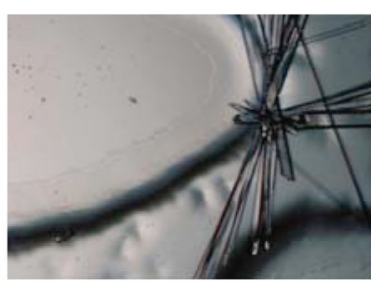

d) Pore plugging, $t=45 \mathrm{~min}$.

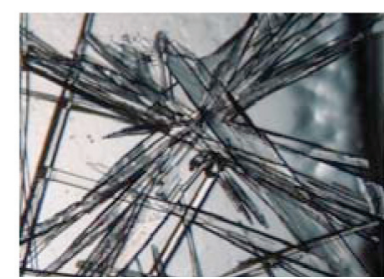
f) Complete plugging of the pore,
$t=100 \mathrm{~min}$.
Figure 6

Different stages in monitoring the precipitation of $\mathrm{CaSO}_{4}$ on the micromodel pattern.

easily deposits on the rough surfaces and is distributed in a non-uniform manner in the micromodel pattern.

The employed method for estimating the rate of scale deposition and the consequence rate of permeability reduction was based on the results of the well known Darcy law:

in which:

$$
\frac{K(t)}{K_{i}}=\frac{\Delta P_{i}}{\Delta P(t)}
$$

- $K_{i}$ : the initial value of the absolute permeability of the pattern;

- $K(t)$ : the absolute permeability of the pattern at each instance;

- $\Delta P_{i}$ : the initial pressure drop along the pattern, $P_{i}-P^{*}$;

- $\Delta P(t)$ : the pressure drop along the pattern at each instant of the time, $\Delta P(t)=P(t)-P^{*}$;

$-P^{*}$ : the pressure drop along the injection pipe before connecting to the inlet port.

For measurement of $P^{*}$, the injection ports are opened to the atmosphere at the desired injection rate and after the 


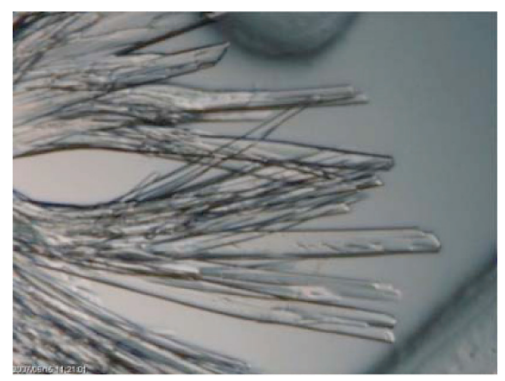

Figure 7

Typical crystal structure of $\mathrm{CaSO}_{4}$.

establishment of a constant value for the pressure, it was recorded. Note that, the main reason of permeability reduction is due to porosity reduction by pore plugging.

\section{RESULTS AND DISCUSSION}

Figure 7 depicts a sample of calcium sulphate scale crystal, which has been deposited in a pore. The overall crystal structure of this kind of scale in all runs looks like "Chicken Roost". The growth of calcium sulphate crystals is initiated from the pore and throat walls and extended toward the center of the pore space. In the following section, the effect of different parameters on the severity of permeability reduction by precipitation of calcium sulphate is given.

\subsection{Effect of Temperature}

To study the effect of temperature on the permeability reduction, flooding Runs \# 1, 2, and 3 were performed at temperatures of 70,80 , and $95^{\circ} \mathrm{C}$, respectively. All other parameters were maintained constant and the values are provided in Table 1. The results indicated that as the temperature increases the tendency toward precipitation increases as well. This result is consistent with the fact that the supersaturation of $\mathrm{CaSO}_{4}$ is an increasing function of temperature. At higher temperatures, the crystals size became smaller while the scale accumulation process has been accelerated in pores and throats (see Fig. 8).

Figure 9 demonstrates the change of permeability versus injected pore volume in the micromodel. One may suggest that the fluctuations in the graph are attributed to the particle entrainment. This phenomenon occurs when a relatively great amount of materials deposit on the porous media, which is accompanied with an increase in pressure drop. This pressure drop forces the particles to start moving further, which returns the pressure drop to its usual trend again.

As the difference between the degree of supersaturation increases the distance between the related curves in Figure 9

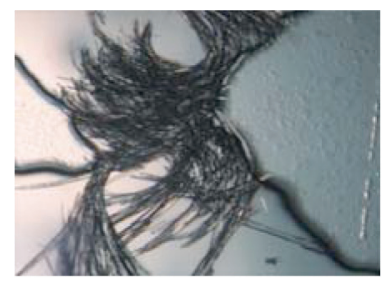

a) Run \#1, Region 3B

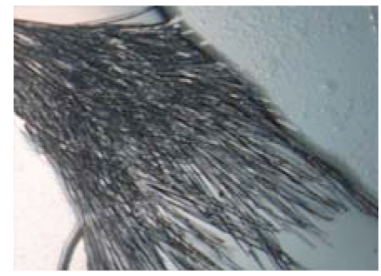

c) Run \#2, Region 4A

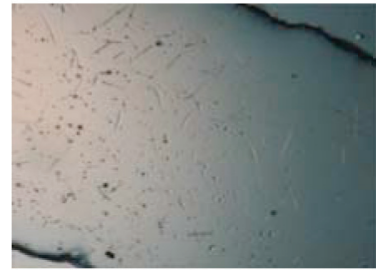

e) Run \#3, Region m1

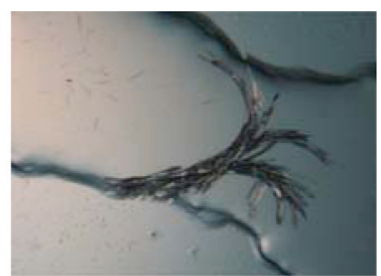

b) Run \#1, Region 1B

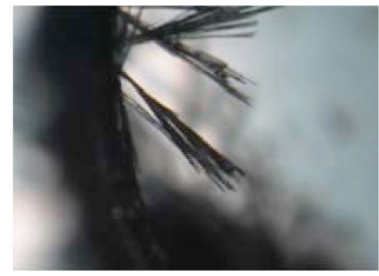

d) Run \#2, Region 4B

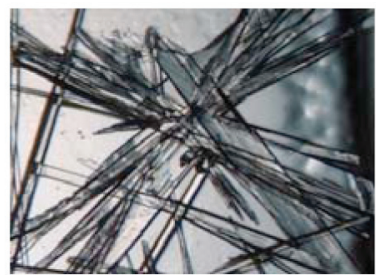

f) Run \#3, between Regions $1 \mathrm{~A}$ and $1 \mathrm{~B}$
Figure 8

Effect of temperature on the precipitation of $\mathrm{CaSO}_{4}$ on the micromodel pattern.

increases as well. As the time passes (more pore volume is injected), the rate of permeability reduction decreases. Several factors may cause this observation. The surface properties of the glass which has been in contact with the solutions and has already adsorbed some scales changes and this affects the retention affinity of it. Moreover, the change in permeability and hence pressure drop, which is caused by entrainment of the already precipitated materials may also influence this behaviour.

\subsection{Effect of Concentration (Supersaturation Index)}

To investigate the effect of $\mathrm{Ca}^{+2}$ and $\mathrm{SO}_{4}^{-2}$ concentrations on the precipitation reaction, flooding Runs \# 4, 2, and 5 were performed at the average brine supersaturation of $1.55,2.0$, and 2.4, respectively. The other parameters remained fixed and the values are given in Table 2.

Figure 10 clearly shows that, as expected the effect of concentration on permeability decay is more pronounced than temperature. The supersaturation is a strong function of concentration. This figure also clarifies that the system attains gradual equilibrium for scaling index of 1.55 and 2.0; while Run \#5 is still far from the equilibrium state and continuing to fall. In addition, at the initial time, the slope of 


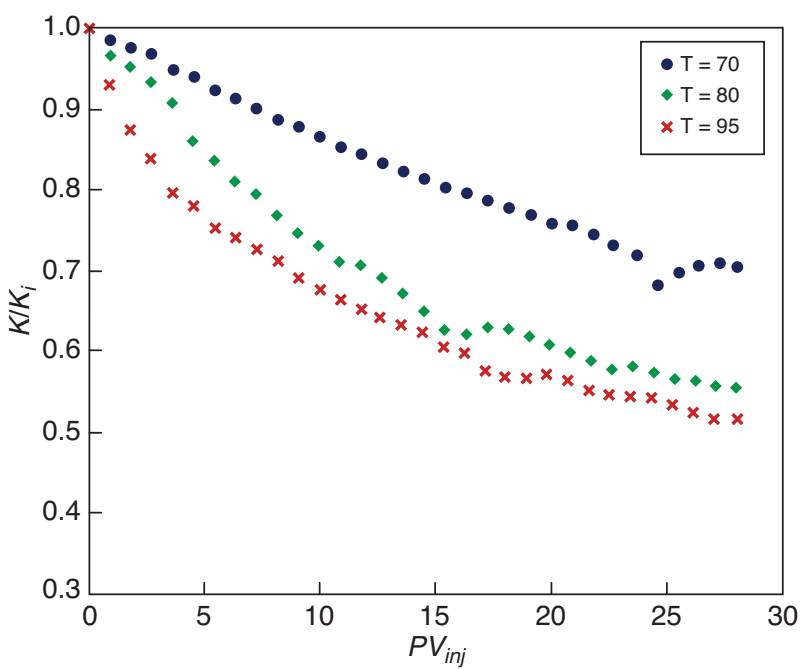

Figure 9

Effect of temperature on permeability reduction: $K / K_{i}$ as a function of injected pore volume of fluids at three different temperatures.

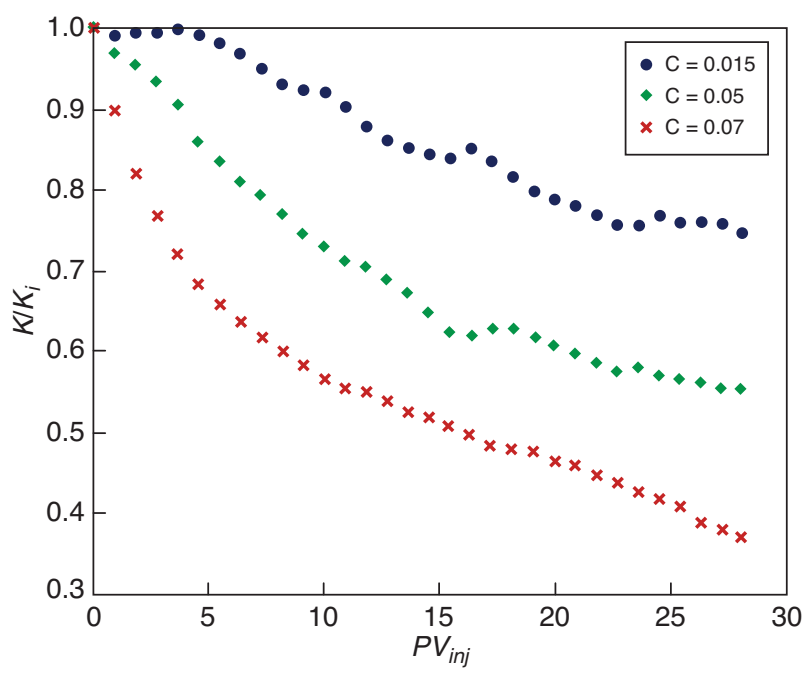

Figure 10

Effect of concentration on permeability reduction: $K / K_{i}$ as a function of injected pore volume for three different concentrations.

this curve is high and then it levels off. This is attributed to the fast occurrence of deposition reaction. This is accompanied with a rapid growth of crystals in pores and throats. For this run, deposition took place immediately in the mixing zone and extended to the whole flooding zone. The deposited solids were quite dense and a completed plugging of the pore throats was observed (see Fig. 11a to Fig. 11d).
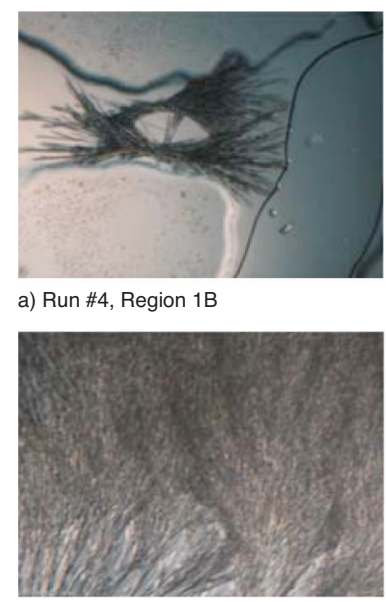

c) Run \#5, Region 1C

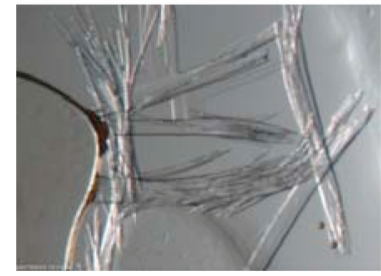

e) Run \#6, Region 2A

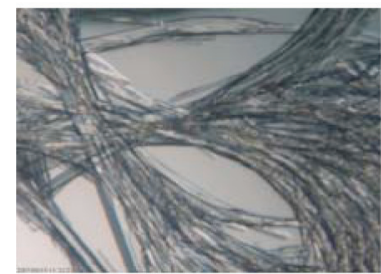

g) Run \#7, Region 2C a) Run \#4, Region 1B

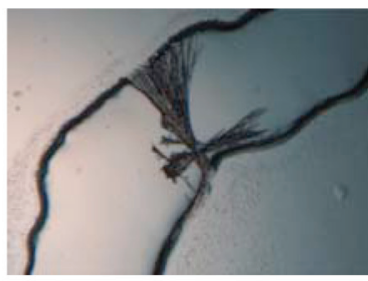

b) Run \#4, Region 3B

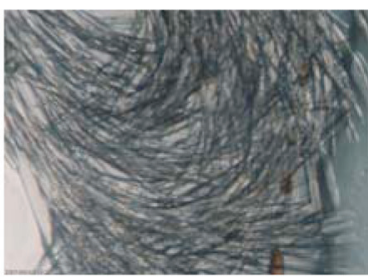

d) Run \#5, Region 3B

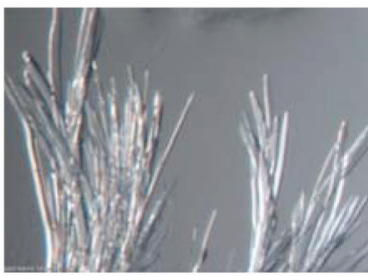

f) Run \#6, Region $1 \mathrm{C}$

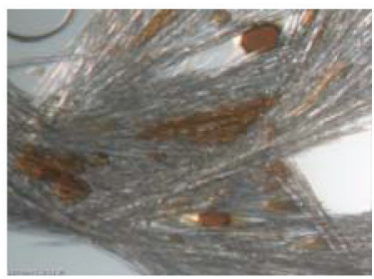

h) Run \#7, Region 3B
Figure 11

Effect of concentration (a-d) and flow rate (e-h) on the precipitation of $\mathrm{CaSO}_{4}$ on the micromodel pattern.

\subsection{Effect of Flow Rate}

To examine the effect of flow rate on the scaling reaction, flooding Runs \# 6, 2, and 7 were performed at the flow rates of $0.004,0.008$, and $0.012 \mathrm{cc} / \mathrm{min}$, respectively. The other invariant parameters are presented in Table 3 . As shown in Figure 12, higher velocity of fluids causes more permeability damage when other parameters are fixed. This was explained by the fact that as the flow rate increases the better mixing of the brine solutions is accomplished and also more collisions between the dissolved ions (due to the tortuous nature of the flow paths) take place, which promote the reaction. For all considered flow rates, the permeability reduction curves almost stabilize at the end of the experiments. At lower velocities the crystal branches are coarser but do not fill the pore space completely (see Fig. 11e to Fig. 11h). 


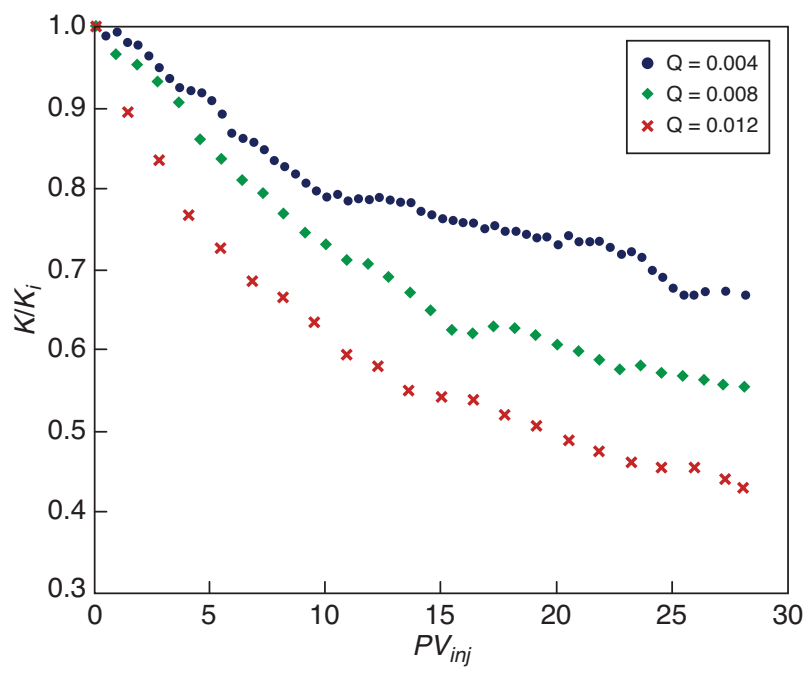

Figure 12

Effect of flow rate on permeability reduction: $K / K i$ as a function of injected pore volume for three different flow rates.

\section{ERROR ANALYSIS OF THE EXPERIMENTS}

The error in the calculated results will depend upon the errors in the measurements from which the results are calculated.

The variations of permeability versus pore volumes of injected fluid were measured by applying Darcy's law for single phase flow:

$$
Q=\beta \frac{K A}{\mu} \frac{\Delta P}{L}
$$

Solving Equation (13) for $K$ yields:

$$
K=\frac{\mu L}{\beta A} \frac{Q}{\Delta P}
$$

$\mathrm{Bu}$ and Damsleth [20] introduced the uncertainties in permeability measurements as follows:

$$
\frac{\Delta K}{K}=\sqrt{\left(\frac{\Delta \mu}{\mu}\right)^{2}+\left(\frac{\Delta L}{L}\right)^{2}+\left(\frac{\Delta A}{A}\right)^{2}+\left(\frac{\Delta Q}{Q}\right)^{2}+\left(\frac{\Delta P}{P}\right)^{2}}
$$

$\Delta \mu, \Delta L, \Delta A, \Delta Q, \Delta P$ represent the errors or uncertainties associated with these quantities. The accuracies and errors associated with the experimental equipment are given in Table 4.

TABLE 4

Accuracy and error of the equipments

\begin{tabular}{c|c|c}
\hline Equipment & Accuracy & \%Error \\
\hline Quizix pump & $0.0001 \mathrm{cc} / \mathrm{min}$ & 1 \\
\hline Pressure transducer & $0.1 \mathrm{Psia}$ & 1 \\
\hline
\end{tabular}

The inaccuracy in calculating the area of the patterns was obtained $0.00000011 \mathrm{~cm}^{2}$ and for its length was $0.1 \mathrm{~cm}$. Substitution of desired values in Equation (15) yields:

$$
\begin{gathered}
\text { Error }=\sqrt{(0)^{2}+\left(\frac{0.1}{7.5}\right)^{2}+\left(\frac{1.1 E-07}{6.4 E-07}\right)^{2}+(0.01)^{2}+(0.01)^{2}} \\
\text { Error }=0.0457 \text { or } 4.57 \%
\end{gathered}
$$

\section{PREDICTION OF $\mathrm{CaSO}_{4}$ PRECIPITATION FORMATION DAMAGE}

It was obvious from the depicted permeability ratio curves that the deposition of $\mathrm{CaSO}_{4}$ manifests a functional form of permeability reduction due to the effect of different parameters. Therefore, an exponential functionality (correlation) of the assumed parameters is proposed and the involved adjustable exponents are determined by using an optimization algorithm which gives global optimized values of exponents, Genetic Algorithm.

Many relationships were proposed to find the best correlation. The first one was a four parameter correlation that incorporated all physical properties $\left(T, Q, P V_{i n j}\right.$ and $\left.S S\right)$. It was found that this correlation could fit the experimental data with reasonable accuracy with 50 different set of unique values. The developed Genetic Algorithm curve fitting utility was used to find the adjustable exponent. The proposed correlation was as follow:

$$
\frac{K}{K_{i}}=\left(1+P V_{i n j}^{\alpha_{1}} \cdot Q^{\alpha_{2}} T^{\alpha_{3}}\right)^{-S S . \alpha_{4}}
$$

Although this correlation was flexible enough to predict the permeability change versus injected pore volume with good accuracy, the exponents were not unique and vary in a wide range from -15 to +15 for any $\alpha$. In addition, the above relation is not dimensionally consistent in the right and the left hand sides and therefore requires modification.

It was found that the exponent $\left(\alpha_{1}, \alpha_{2}\right)$, and $\left(\alpha_{3}, \alpha_{4}\right)$, are interrelated. When a set of solutions (exponents) are generated by the utility, both figures in each pair increase or decrease simultaneously. Therefore, one figure of each pair can be omitted and its effect transferred to the other remaining one.

These observations indicated that a dimensionless analysis was required. Since the supersaturation is a monotonically increasing function of temperature and concentration, term $T^{\alpha_{3}}$ was ignored and replaced by SS. On the other hand, term $Q^{\alpha_{2}}$ was substituted by a special representation of Reynolds Number. The usual definition of Reynolds Number is as follow:

$$
R e=\frac{\rho u L}{\mu}
$$

the term $u$ (velocity) in this definition may be replaced by:

$$
u_{a}=\frac{u}{\phi}
$$

in which $\phi$ is the porosity of the porous media. 
The final proposed dimensionless correlation is as follow:

$$
\frac{K}{K_{i}}=\exp \left[-\left(P V_{i n j} \times 0.003 R e\right)^{\beta_{1}} \times(S S-1) \times(S S)^{\beta_{2}}\right]
$$

in which:

- $P V_{\text {inj }}:$ injected pore volume;

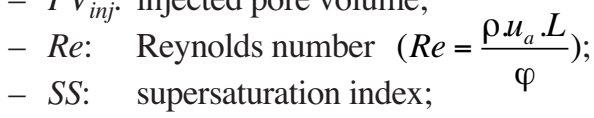

- $\beta_{1}, \beta_{2}$ : adjustable exponents (determined by utility).

As pointed out, this correlation incorporates all physical properties that affect the experimental data $\left(T, Q, P V_{i n j}\right.$, and $S S)$. Term $(S S-1)$ defines how much the system is far from the equilibrium conditions, i.e. $S S=1 . T$ is inherent in $S S$ parameter and Reynolds number incorporates the flooding velocities.

The data set of each experiment was fitted by this correlation and the proper values of the exponent pair $\left(\beta_{1}, \beta_{2}\right)$ obtained. The results indicated that the value of preceding coefficient of Reynolds number is almost constant and equal to 0.003 , so its value was set constant. In addition, the values of $\beta_{1}$ and $\beta_{2}$ are limited to range of 0.3 to 2.0. Although it was possible to get reasonable match for each data set separately with different values of $\left(\beta_{1}, \beta_{2}\right)$, it was tried to determine and define these values to get a reasonable match for all experimental data once. Therefore, for any set of experiment $\left(\beta_{1}, \beta_{2}\right)$ were determined separately and the final values were obtained as the arithmetic average of the values extracted from all of the data sets. The outcome was as follow:

$$
\frac{K}{K_{i}}=\exp \left[-\left(P V_{i n j} \times 0.003 R e\right)^{0.7} \times(S S-1) \times(S S)^{0.95}\right]
$$

Note that in the above correlation the $P V_{i n j}$ is always the primary variable and depending on the experiment condition under consideration the values of $R e$ and $S S$ vary accordingly.

In investigating the effect of temperature, the secondary important variable would be $S S$ which inherently represents this effect. Comparison between correlation results and experimental data is shown in Figure 13. Table 5 lists the adjustments and associated errors of the correlation for different runs.

In studying the effect of concentration, the secondary variable would be SS. Comparison between correlation results and experimental data is shown in Figure 14. Table 6 lists the adjustments and associated errors of the correlation for different runs.

In examining the effect of flow rate, the secondary variable would be $R e$ which inherently represents this effect. Comparison between correlation results and experimental data is shown in Figure 15. Table 7 lists the adjustments and associated errors of the correlation for different runs.

The proposed correlation shows reasonable accuracy especially at the late time of the injection period, which is of more interest than the early time behaviour.

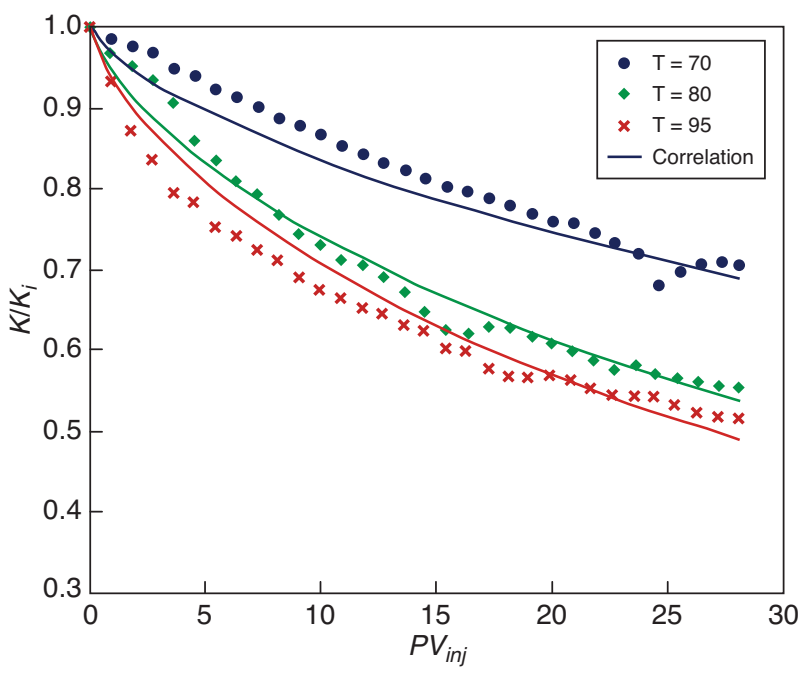

Figure 13

Effect of temperature: $K / K_{i}$ as a function of injected pore volume. Experimental data is represented by filled symbols and correlation data is presented by solid lines.

As explained before, it is possible to get a better match by using different and special set of $\left(\beta_{1}, \beta_{2}\right)$ for each experimental data set. This matter is explained in Figure 16 and Table 8.

TABLE 5

Effect of temperature: correlation adjustments and error information

\begin{tabular}{c|c|c}
\hline Run \# & Correlation variables & Standard deviation \\
\hline 1 & $P V_{i n j}, S S=1.7$ & 0.026 \\
\hline 2 & $P V_{i n j}, S S=2.0$ & 0.019 \\
\hline 3 & $P V_{i n j}, S S=2.1$ & 0.026 \\
\hline
\end{tabular}

TABLE 6

Effect of concentration: correlation adjustments and error information

\begin{tabular}{c|c|c}
\hline Run \# & Correlation variables & Standard deviation \\
\hline 4 & $P V_{i n j}, S S=1.55$ & 0.032 \\
\hline 2 & $P V_{i n j}, S S=2.0$ & 0.019 \\
\hline 6 & $P V_{i n j}, S S=2.4$ & 0.035 \\
\hline
\end{tabular}

TABLE 7

Effect of flow rate: correlation adjustments and error information

\begin{tabular}{c|c|c}
\hline Run \# & Correlation variables & Standard deviation \\
\hline 6 & $P V_{i n j}, R e=1.17$ & 0.063 \\
\hline 2 & $P V_{i n j}, R e=2.34$ & 0.019 \\
\hline 7 & $P V_{i n j}, R e=3.52$ & 0.151 \\
\hline
\end{tabular}




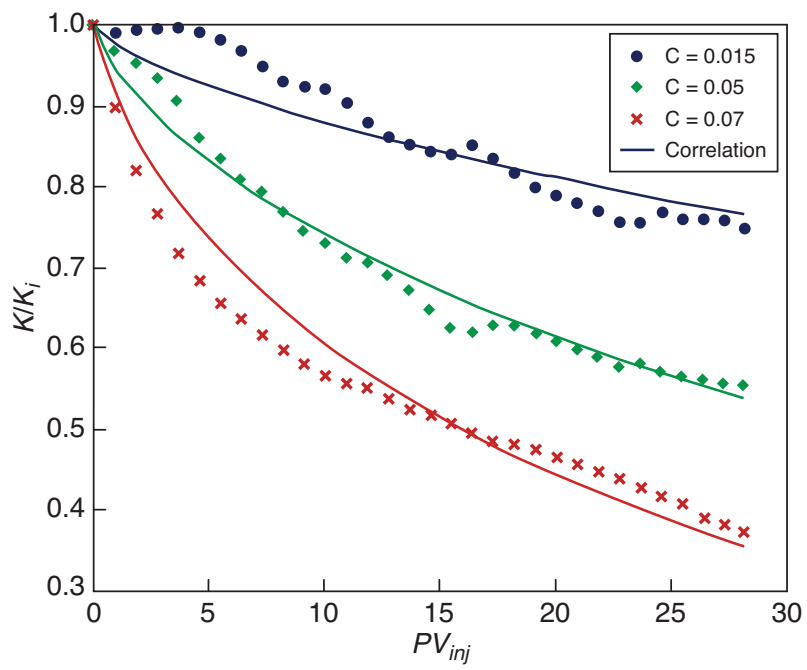

Figure 14

Effect of concentration: $K / K_{i}$ as a function of injected pore volume. Experimental data is represented by filled symbols and correlation data is presented by solid lines.

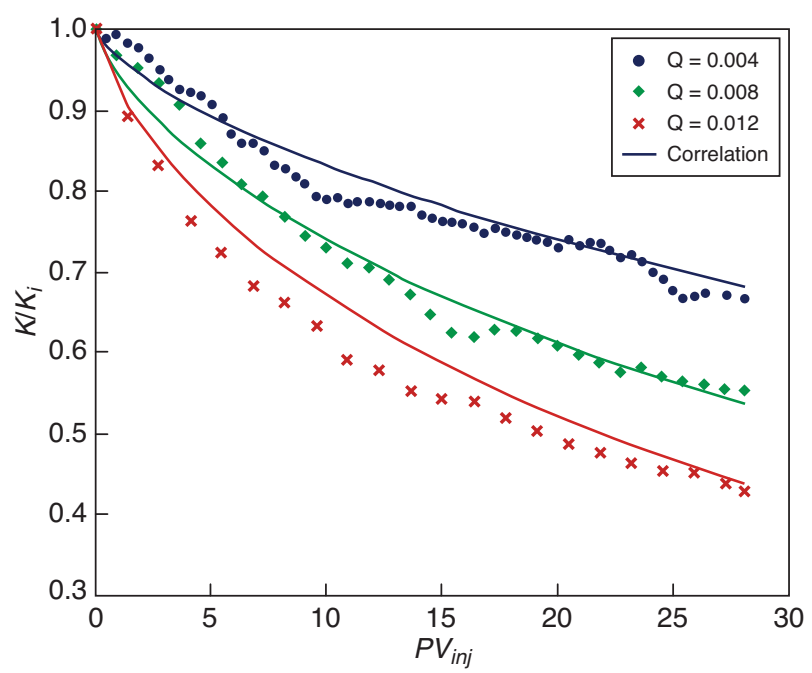

Figure 15

Effect of flow rate: $K / K_{i}$ as a function of injected pore volume. Experimental data is represented by filled symbols and correlation data is presented by solid lines.

\section{TABLE 8}

Effect of selected values for $\left(\beta_{1}, \beta_{2}\right)$ set on the accuracy of the correlation predictions

\begin{tabular}{c|c|c|c}
\hline Run \# & Correlation variables & $\left(\beta_{1}, \beta_{2}\right)$ & Standard deviation \\
\hline 7 & $P V_{i n j}, \operatorname{Re}=3.52$ & $(0.7,0.95)$ & 0.151 \\
\hline 7 & $P V_{i n j}, \operatorname{Re}=3.52$ & $(0.6,0.88)$ & 0.038 \\
\hline
\end{tabular}

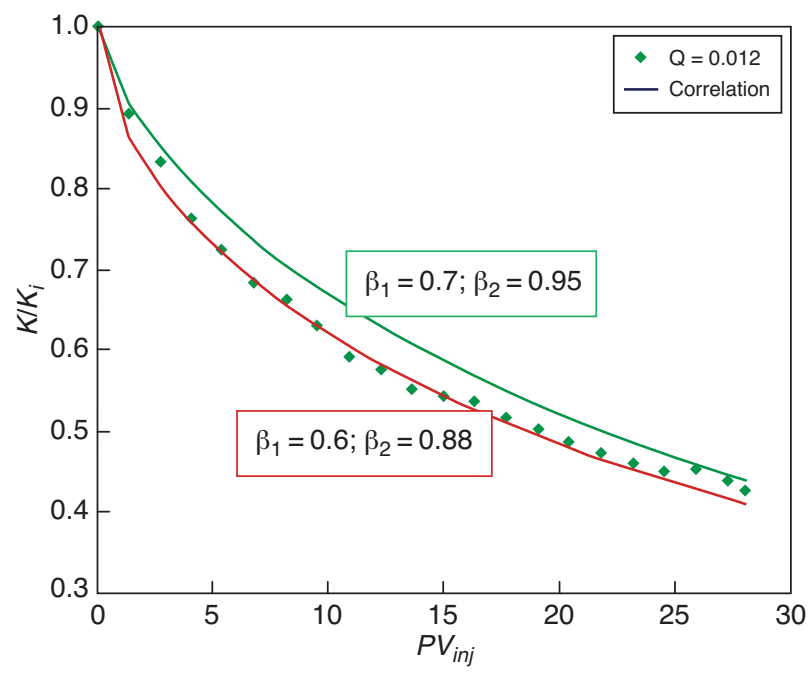

Figure 16

Difference in the accuracy of predicted results by using specific values of $\left(\beta_{1}, \beta_{2}\right)$, for each experiment (red curve) and using the average values of all experiments (green curve). Experimental data is represented by filled symbols and correlation data is presented by solid lines.

\section{CONCLUSIONS}

This study was aimed at investigating the effect of different parameters on permeability reduction rate due to deposition of calcium sulphate scale in porous media. Sulphate scales are the most common oil field scales encountered in oil field operations. Laboratory flooding experiments were conducted in which a supersaturated synthetic brine containing a blend of brine solutions had been injected through micromodel glass sandstone samples. Experiments were conducted at various sets of conditions such as temperature, brine ionic strength (supersaturation index), and injection flow rate. A general correlation for predication this reduction rate was also developed. The developed correlation incorporated some kinetic and hydrodynamic parameters. The equation has been validated via the experimental results.

Based on the presented results, the following conclusions can be drawn:

- a simple and sound methodology for laboratory investigation of scale precipitation in porous media has been devised;

- the extension and distribution of scale formation and deposition can be easily observed from the beginning of the process (nucleation stage) to the end (pore plugging);

- the scaling position in porous media is absolutely random. The scale easily deposits on rough surfaces and heterogeneously distributed in the micromodel; 
- the migrating and depositing of scale crystals is the main mechanism that causes scaling damage and permeability reduction.

Due to $\mathrm{CaSO}_{4}$ precipitation reaction in glass micromodel pattern:

- the following two parameter correlation for $\mathrm{CaSO}_{4}$ scale precipitation in glass micromodel patterns fitted the experimental data of permeability decay curve well:

$$
\frac{K}{K_{i}}=\exp \left[-\left(P V_{i n j} \times 0.003 R e\right)^{0.7} \times(S S-1) \times(S S)^{0.95}\right]
$$

This equation yielded a mean absolute error of $11.16 \%$;

- the proposed correlation incorporates all the physical parameters that affect the process in dimensionless form.

\section{ACKNOWLEDGMENT}

The assistance of Mr. Salimi, the technician of Petroleum Research Center of Tehran in fulfilling the experiments is appreciated. The authors also greatly appreciate Mr. Farzaneh for his unconditional availability and desire to share his scientific knowledge and experience to carry out this research.

\section{REFERENCES}

1 Krueger R.F. (1986) An Overview of Formation Damage and Well Productivity in Oil Field Operation, J. Petrol. Technol. 38, 131-152.

2 Lasater R.M., Gardner T.R., Glasscock F.M. (1968) Scale Deposits Are Controlled Now with Liquid Inhibitors, Oil Gas J. 66, 88-93.

3 Khatib Z.I. (1994) Prediction of Formation Damage Due to Suspended Solids: Modeling Approach of Filter Cake Buildup in Injectors. SPE 28488, presented at the SPE Annual Technical Conference and Exhibition, 25-28 September, New Orleans, Louisiana, USA.

4 Yuan M.D., Todd A.C. (1991) Prediction of Sulfate Scaling Tendency in Oil Field Operations, SPE Prod. Eng. J. 6, 63-72.

5 Vetter O.J. (1976) Oil field Scale - Can We Handle It? J. Petrol. Technol. 28, 1402-1408.

6 Abu-Khamsin S.A., Ahmad S.J. (2005) Laboratory Study on Precipitation of Calcium Sulphate in Berea Sandstone Cores, SPE 106336, SPE Technical Symposium of Saudi Arabia Section, 14-16 May, Dhahran, Saudi Arabia.
7 Bezmer C., Bauer K.A. (1969) Carbonate Scale Deposition: A Well Packing Technique with Controlled Solubility Phosphates, J. Petrol. Technol. 21, 505-514.

8 Vetter O.J., Farone W.A., Veith E., Lankford S. (1987) Calcium Carbonate Scale Considerations: A Practical Approach, SPE 17009, SPE Production Technology Symposium, 16-17 November, Lubbock, Texas, USA.

9 Vetter O.J., Kandarpa V., Harouaka A. (1982) Prediction of Scale Problems Due to Injection of Incompatible Waters, J. Petrol. Technol. 34, 273-284.

10 Read P.A., Ringen J.K. (1982) The Use of Laboratory Tests to Evaluate Scaling Problems during Water Injection, SPE 10593, SPE Oilfield and Geothermal Chemistry Symposium, 25-27 January, Dallas, Texas, USA.

11 Xiaojuanm R., Pingchang W., Zhihao Q., Chengen S. (2006) Studying the Scaling Mechanism of Low-Permeability Reservoirs Using Visual Real-Sand Micromodel, SPE 100452, SPE International Oilfield Scale Symposium, 31 May-1 June, Aberdeen, UK.

12 Wei S., Zhihao Q., Guo-Qing T. (2004) Characterization of Water Injection in Low Permeable Rock Using Sandstone Micro-Model, SPE 86964, SPE International Thermal Operations and Heavy Oil Symposium and Western Regional Meeting, 16-18 March, Bakersfield, California, USA.

13 Ostroff A.G., Metler A.V. (1966) Solubility of Calcium Sulfate Dihydrate in the System of $\mathrm{NaCl}-\mathrm{MgCl}_{2}-\mathrm{H}_{2} \mathrm{O}$ from 28 to $70^{\circ} \mathrm{C}$, J. Chem. Eng. Data 11, 346-350.

14 Oddo J.E., Tomson M.B. (1994) Why Scale Forms in the Oil Field and Methods to Predict It, SPE Prod. Facil. 9, 47-54.

15 Skoog D.A., West D.M., Holler F.J. (1996) Fundamental of Analytical Chemistry, 7th edition, Saunders College Publishing.

16 Atkins P., Paula J. (2006) Atkins' Physical Chemistry, 8th edition, Oxford University Press.

17 Odd J.E., Thomson M.B. (1982) Simplified Calculations of $\mathrm{CaCO}_{3}$ Saturation at High Temperatures and Pressures in Brine Solutions, J. Petrol. Technol. 34, 1583-1590.

18 Atkinson G., Mecik M. (1997) The Chemistry of Scale Prediction, J.Petrol.Sci.Eng. 17, 113-121.

19 Valone F.W., Skillern K.R. (1982) An Improved Technique for Predicting the Severity of Calcium Carbonate. SPE 10594, SPE Oilfield and Geothermal Chemistry Symposium, 25-27 January, Dallas, Texas, USA.

20 Bu T., Damsleth E. (1996) Errors and Uncertainties in Reservoir Performance Predictions, SPE Formation Evaluation 11, 194-200.

Final manuscript received in July 2008 Published online in July 2009

Copyright (C) 2009 Institut français du pétrole

Permission to make digital or hard copies of part or all of this work for personal or classroom use is granted without fee provided that copies are not made or distributed for profit or commercial advantage and that copies bear this notice and the full citation on the first page. Copyrights for components of this work owned by others than IFP must be honored. Abstracting with credit is permitted. To copy otherwise, to republish, to post on servers, or to redistribute to lists, requires prior specific permission and/or a fee: Request permission from Documentation, Institut français du pétrole, fax. +33147527078 , or revueogst@ifp.fr. 